\title{
Empirical Research on Industrial Design Contribution Rate under Statistical Frame
}

\author{
Xiaojing Liu ${ }^{1}$, Ying Liu ${ }^{1}$ and Xinyuan Xue ${ }^{1}$ \\ ${ }^{1}$ Central South University, School of architecture and art, 410083 Changsha City, Hunan, China
}

\begin{abstract}
This paper studies the evaluation method of industrial design contribution rate from the statistical frame, strives to realize the extension of research results and the replication of research method. This paper firstly identifies the connecting points with the statistics of national scientific activities through streamlining the relationship between industrial design and R\&D; and then it selects the appropriate calculating model and variants according to the characteristics of industrial design, as well as established the accumulating effects regression model as per the development rules of product; finally it applies the statistical data of random sampling to calculate the industrial rate of ShunDe District in 2012 and analyzes the research results
\end{abstract}

\section{Introduction}

Currently the trend of industrial design leading the innovation and upgrading of enterprise is blooming. However, when discussing how much value the industrial design can bring, people always mention the research results of the United States, UK and Japan, and there is little empirical research data involved with the value contribution rate of industrial design in China ${ }^{[2-3]}$. In 2011, Beijing Industrial Design Promotion Center has calculated the industrial contribution rate in Beijing through the questionnaire and the survey data was $1: 12.99^{[1]}$. This significant research attempt has been attracting a broad attention. However, the research method of questionnaire is consuming time and stamina, which is inconvenient to duplicate and promote. In addition, the objective aspects in the course of collecting data and samples need to be further improved. Such current situation has demonstrated that the research on the field of industrial design value evaluation still needs to be deepened, so as to enable the management level of industrial design to follow up the step of industry development.

\section{Why making research on the industrial design contribution rate}

\subsection{Industrial design contribution rate}

The contribution rate is one of the indexes for analyzing the economic benefit. It refers to the rate between the number of effective or useful results and the resources consumption and occupation volume, and that is, the rate between output volume and input volume. The contribution rate is usually used for analyzing the degree

\footnotetext{
*Corresponding author: ${ }^{\text {a } 81413450 @ q q . c o m}$
}

of effects ofeach factor in the economic increase. This index represents the driving force of industrial design to economy, and it can be used to evaluate the health degree of industrial design development.

Industrial design is a creative activity with multiple input and multiple output. Its input includes capital, manpower, equipment, modelling etc. And its output includes economic benefit, social benefit, environmental benefit etc. When performing the evaluation of industrial design contribution rate, the output of economic benefit shall be taken as the main data.

\subsection{Significance of researching contribution rate}

It is well known that the industrial design plays an important strategically role in the transformation and upgrading of national manufacturing industry. However, what is exactly the value of industrial design? How to calculate it? What the differences between different industries and environments? Such series of problems have directly reflected the management level of industrial design for one country. The industrial contribution rate is an important evaluation index to reflect the value of industrial design, which can directly evaluate the entire status of industrial design development. The scientific evaluation method of industrial design contribution rate can realize the long-term monitoring to the development status of targeted object industrial design, as well as carry out the horizontal comparison with the other objects to discover the characteristics and advantages of their own development.

We can analyze the significance of industrial design contribution rate from four levels. From the government level, it is able to help the governments to understand the entire development status of industrial design, differences in regions and industries to facilitate the 
issuance of relevant targeted polities. From the industry level, it is help to comprehensively understand the degree of correlation between industrial design and industry development, as well as draft the industry development strategies from their own characteristics and advantages. From the enterprise level, it can help us pragmatically understand the economic benefit of enterprises brought by the industrial design so as to help the enterprises transform and upgrade, as well as stimulate the limited resources to distribute reasonably. From the designing company level, it follows the contribution rate of industrial design project to reflect the designing capacity of company, so as to directly reflect the competition strength during the tendering and quotation of project.

\section{How to calculate the industrial design contribution rate}

\subsection{Industrial design under the statistical frame}

In order to recognize and analyze the industrial design contribution rate in a scientific way, it is necessary to find the indexes and data that can reflect the characteristics of industrial design and ensure its objectivity, availability and consistency. However, in order to ensure that the indexes and data are consistent on the multiple levels of governments, industry and enterprises, currently the most available way is to connect with the statistical frame. First of all, understand the quantitative means and analyze methods of the current statistical frame in China to the statistical indexes of industrial design and relevant activities, and then identify the specific indexes representing the industry characteristics of industrial design, as well as clarify the relationship between these indexes and current statistical indexes.

Streamline the concept and scope of industrial design from the national statistical frame, identify that the industrial design belongs to the statistics of enterprise science and technology activities included in the scope of R\&D (Research \& Development). R\&D covers most of the basic research, application research and test development. However, the research activities of industrial design are included in the application research. The prototype creativity and modeling creativity of industrial design are included in its test development. The specific relationship can be indicated by the following figure $1:^{[4]}$

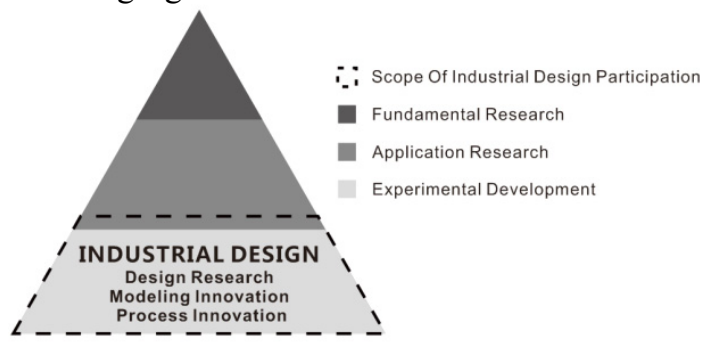

Figure 1 The relationship between R\&D and industrial design in the statistical category of scientific and technological activities of enterprises
R\&D is a very important index in the scientific activity statistics. The government perform routine statistics every year, and carry out the special general survey every ten years, and the rules for statistics have become mature. We can streamline the relevant indexes of industrial design from the statistical frame of $R \& D$ according to the relationship structure between industrial design and $\mathrm{R} \& \mathrm{D}$, as well as abstract the statistical data to carry out the research on the industrial design contribution rate.

\subsection{Selection of model and variable}

Through comparing and analyzing hundreds of relevant literature on the research methods of contribution rate at home and abroad, this paper mainly focuses on the contribution rate calculation of $R \& D$ or scientific resources, and applies the regression analysis method, index method and ratio method. We finally apply the multiple linear regression models to calculate the contribution rate of industrial design through weighting the strength of various research methods, combining the industry properties of industrial design and considering the adaptability to the statistical frame. ${ }^{[5-6]}$

The key point of applying the regression model to calculate the contribution rate is the selection of independent variant, dependent variable and control variable.

The capital investment of product development is selected as the independent variable. It includes the input indexes of industrial design e.g. operational capital, human resource, equipment and facilities, conceptual creativity etc. It is able to transform each input index into the fund amount to unify the quantitative indexes during specifically selecting the independent variables. The sites for equipment and facilities are finally converted into the currency funds to reckon in the product cost, manpower input can be converted into the remuneration to reckon in the input cost. Therefore, from the perspective of cost accounting, the capital input of industrial design can cover the input of various resources, which can also comprehensively weight the $R \& D$ input cost of enterprises. In the annual scientific statistics, it is able to conclude the development expense for new product from the total amount of scientific activities expenses, that is, the expenses of enterprises used for the research, design, research and fabrication of models, as well as test and experiment etc. We can regard the expenses for the development of new product (exclude the expenses of technical improvement that don't belong to the industrial design activities) as the capital input of industrial design for the product development of enterprises.

The sales income of the new product is selected as the dependent variable. The value of industrial design can be reflected by the product financial indexes of enterprises e.g. sale income of new product and production cost reduction etc. The purpose of one enterprise to carry out the industrial design is to increase the sales income of new product, which is the reflection of economic value of industrial design. Therefore, the index of sales income for new product can be taken as the output index, which 
is in line with the properties of industrial design. The sales income of new product in the scientific activities of enterprises is the routine index, and it can collect data directly.

The sales capacity of enterprises is selected as the control variable. The sales capacity of enterprises refers to the capacity of enterprises to enable the customers to accept new product within the shortest time, which is particularly important for new product to obtain the final economic benefit, and it will affect the relationship between the input of industrial design and output of enterprises performance. By referring to the practice of Bouwen Lin, Yikuan Lee etc. in "R\&D intensity and Commercialization orientation effects on financial performance" [7], it utilizes the sales cost to reflect the level of sales capacity. Generally speaking, only the large-scaled enterprises are able to possess the sufficient funds to construct the complete sales channels and sales methods, in which the sale cost is usually high, and it is difficult for the middle-and-small-scaled enterprises to input the capital investment in the sales of new product. We can directly collect the statistical data from the sales cost of a new product, and utilize its natural logarithm to indicate the sales capacity of the new product.

\subsection{Construction of accumulated effect and models}

New product requires several steps from designing R\&D to realizing the commercialization, as well as from just entering into the market to being recognized by market. However, the sharp increase of sales also needs a long process. Therefore, the input of industrial design has a certain hysteretic effect on the output benefit of enterprises, and that is indicated as the product development of industrial design is the continuous accumulation process of multiple-year input and multiple-year output. The input of industrial design is the year-by-year accumulated stock instead of the current-year throughput. The research survey has shown that the average sales period for new product is 3-5 years, and the effective period of new product recognized by China is 3 years. Therefore, it could be considered that the average period of cumulative effect of industrial design is 3 years. By referring to the book named 《Knowledge based Economy》 (1996) on the basic concepts of stock measurement, we can utilize the perpetual inventory(stock) system of physical stock to calculate the accumulated stock of industrial design input within 3 years. ${ }^{[8-10]}$

Drawing on the basic idea of DECD on stock measure, we can build the cumulative effect regression model of industrial design contribution rate ${ }^{[5]}$ :

$$
\mathrm{NPS}_{\mathrm{t}}=\beta_{1} \operatorname{lnME}_{\mathrm{t}-1}+\beta_{2} \mathrm{ID}_{\mathrm{t}-1}+\varepsilon
$$

In which $\mathrm{NPS}_{\mathrm{t}}$ represents the sales income of new product in the year $\mathrm{t}, \mathrm{ME}_{\mathrm{t}-1}$ represents the sales capacity in the $\mathrm{t}-1$ year (natural logarithm of sales expense), $\mathrm{ID}_{\mathrm{t}-1}$ is the cumulative industrial design input in the $\mathrm{t}-1$ year, $\varepsilon$ is the random interference end item. If the cumulative development expense of new product is 0 , the sales income of new product will not exist, thus there will be no regular number.

\section{Empirical analysis of industrial design contribution rate}

\subsection{Source of data and data handling}

In order to empirically analyze the industrial design contribution rate, we strive to connect with the national statistical frame, as well as collect the relatively objective, fair true data of enterprises to generate the continuous and stable data base for the relevant units, enterprises and scholars to analyze. According to the regulations of Statistics Laws of the People's Republic of China and the requirements of scientific statistical annual report policy of National Statistics Bureau, the enterprises declare the performance of scientific activities of enterprises every year to the Statistics Bureau through the Performance Sheet of Scientific Project for the Scaled and Above Industrial Enterprises and Performance Sheet of Scientific Activities for the Scaled and Above Industrial Enterprises. We will take Shunde District as the research object, through research and visit to the statistical departments of enterprises and governments, and randomly collect the data of survey sheets of scientific activities for 60 scaled and above manufacturing enterprises from 2010 to 2012 as the research samples.

In order to eliminate the influences of inflation, we select the consumption index of residents in Foshan City from 2010 to 2012 , carry out the deflation to the output and control variables to conclude the invariable price by taking 2010 as the base period. Substitute the total capital of industrial design input of selected samples from 2010 to 2012 into the perpetual inventory system model to conclude the accumulate stock of industrial design input in 2012.

\subsection{Calculate data and results analysis}

We input the successive 3-year cumulative stock of industrial design input capital, the sales income of enterprises in 2012 and the statistical data of sales expenses for the new product in the software Eviews 6 to calculate the industrial design contribution rate in 2012. The results obtained are shown in table 1:

Table1 Empirical Study on correlation of sales income of new products in industrial design area

\begin{tabular}{|lcccc|}
\hline Variable & Coefficien & Std.Error & t-Statistic & Prob. \\
\hline ME & 590.6990 & 293.7710 & 2.010747 & 0.0490 \\
ID & 101.0295 & 5.418471 & 18.64539 & 0.0000 \\
\hline R-squared & 0.929123 & & D.W & 1.742936 \\
\hline
\end{tabular}

Substitute the results into the above sheet into the regression model to conclude the relationship between the cumulative expense input of industrial design and the sales income for the new product of enterprises as below:

$$
\widehat{N P S}=590.70 M E+101.03 I D
$$

It can be seen from the above Table that $\mathrm{R}^{2}=0929$, which is approaching to 1 , so the fitting degree of model is high. Under the 5\% significance level, these two 
independent variables can be tested via t statistics, which indicates that the independent variable can explain the dependent variable to a great extent. D.W testing value is approaching 2, and the auto-correlation between independent variables is low, which indicates that the modelling is reasonable. The empirical results have shown that the industrial design input has the significant positive correlation with the sales income of a new product. The increase of 1 unit industrial design input can bring 101.03 units of sales income of a new product. The empirical results have shown that the industrial design contribution rate of Shunde District in 2012 is $1: 101.03$. It needs to stress that this value is the overall average level of Shunde District in 2012. If we extend this evaluation method for year-by-year tracking, we can directly understand the actual status of industrial design development of Shunde District.

\section{Conclusions}

Exploring the evaluation method of scientific industrial design contribution rate from the statistical frame, and striving to realize the extension of research results and the re-producibility of research method is a work of great significance. Currently, the research is relying on the domestic exiting statistical regulations and data, the research results can basically reflect the industrial design contribution level of regions and industries. If the management levels of design in enterprises are keeping improving, as well as each index and data have realized to take the enterprises as the subject and segment to each new product development project, it is able to display the industrial design contribution rate of manufacturing enterprises and designing companies by utilizing this calculation method. Thus it is undoubted? to form the four-level integrated consistent evaluation system for governments, industries, manufacturing enterprises and designing companies, which is better advantageous to the technical operation and comparison analysis in the practical work.

But still, there are certainly some problems existing in the research on industrial design contribution rate. Firstly the calculation method only considers the 3-year cumulative input of industrial design for the ordinal product development project, however, the development time for some innovative product projects with breakthrough property usually exceeds 3 years, and the benefit generated by them can be greatly reflected in the products of second-generation and third-generation. Currently it is still unable to identify the method to directly calculate the industrial design cumulative stock for the innovative product with breakthrough property. Secondly, when making research on the industrial design contribution rate in Shunde District, it was able to collect the successive 3-year data samples for only 60 manufacturing enterprises due to the limited objective conditions. If it's during the actual calculation work, the number of samples collected shall be as per the total number of manufacturing enterprises within the area to ensure that the research results have strong representativeness.

\section{Acknowledgment}

The project of the Hunan Province philosophy and Social Science Fund "Research on value and performance evaluation of industrial design", Number:16yba369

\section{Reference}

1. Dongliang Chen, The value of industrial design, Oriental Enterprise Culture,2(2011)

2. Xiaojing Liu, Research on value evaluation of industrial design, An empirical research report based on the development status of Shunde District , Tianjin People's Fine Arts Publishing House , (2014)

3. Crawford, M., and A. Di Benedetto. New products management (9th ed.). New York: McGraw-Hill/Irwin, (2008)

4. Statistical report system of enterprise (unit) scientific and technological activities, National Bureau of Statistics of the People's Republic of China, 12(2013)

5. OECD, Knowledeg-Based Economy, Beijing Machinery Industry Press, ( 1996)

6. Haoxiang Wang, The correlation between R\&D cost input and enterprise value- Based on the data of high and new technology enterprises listed in China, Capital University of Economics and Business, PHD, Capital University of Economics and Business , Beijing (2012)

7. BW Lin, Y Lee, SC Hung, R\&D intensity and commercialization orientation effects on financial performance, Journal of Business Research , 59 ,6, (2006)

8. Bouwen Lin, Yikuan Lee and Shichang Hung, $R \& D$ intensity and Commercialization orientation effects on financial performance, Journal of Business Research,(2006)

9. Gemser, Gerda Leenders, and Mark A.A. How Integrating Industrial Design in the Product Development Process Impacts on Company Performance, Journal of Product Innovation, 18(2001)

10. Maohua Jie, Yuanyuan Wang, R\&D investment and enterprise value of resource-based enterprises, Journal of Industrial technology,8(2011) 